\title{
Clinical Utility of miRNA-1, miRNA-29g and miRNA-133s Plasma Levels in Prostate Cancer Patients With High-Intensity Training After Androgen-Deprivation Therapy
}

\author{
A. GAZOVA ${ }^{1}$, A. SAMAKOVA ${ }^{3}$, E. LACZO ${ }^{4}$, D. HAMAR ${ }^{4}$, M. POLAKOVICOVÁ ${ }^{4,5}$, \\ M. JURIKOVA ${ }^{6}$, J. KYSELOVIC ${ }^{2}$
}

${ }^{1}$ Institute of Pharmacology and Clinical Pharmacology, Faculty of Medicine, Comenius University Bratislava, Slovak Republic, ${ }^{2} 5$ th Department of Internal Medicine, Faculty of Medicine, Comenius University Bratislava, University Hospital Bratislava, Slovak Republic, ${ }^{3}$ Department of Pharmacology and Toxicology, Faculty of Pharmacy, Comenius University Bratislava, Slovak Republic, ${ }^{4}$ Faculty of Physical Education and Sports, Comenius University Bratislava, Slovak Republic, ${ }^{5}$ Faculty of Pharmacy, Comenius University Bratislava, Slovak Republic, ${ }^{6}$ Institute of Histology and Embryology, Faculty of Medicine, Comenius University Bratislava, Slovak Republic

Received June 8, 2019

Accepted September 20, 2019

\section{Summary}

The randomized trials showed that the addition of training resistance program to androgen-deprivation therapy (ADT) had many beneficial effects for prostate cancer (PC) patients (significant protective effect on the volume of muscle mass) and the studies have revealed a panel of miRNAs, which are deregulate in PC and may serve as promising biomarkers of PC risk. The primary aim of our present study was to investigate the effect of exercise training to changes in body composition (muscle strength) and the secondary endpoint was to investigate the impact of an exercise training program on plasma levels of selected myogenic microRNAs (miRNAs) (miRNA-1, miRNA-29b, and miRNA-133) in PC patients undergoing the ADT. Effect of ADT and exercise intervention showed significant increase (experimental group vs. control group) the changes in body composition, free testosterone levels, IL-6 and plasma levels of myogenic miRNAs and significant reduced insulin serum levels. In conclusion, resistance training with $\mathrm{ADT}$ in the treatment of PC significantly changed the physical and metabolic function and the plasma levels of specific myogenic miRNAs. Our data support with the other publicized results.

\section{Key words}

Prostate cancer - Androgen-deprivation therapy • miRNAs • Training

\section{Corresponding author}

A. Gazova, Faculty of Medicine, Comenius University, Špitálska 24,813 72 Bratislava, Slovak Republic. E-mail: andrea.gazova@fmed.uniba.sk

\section{Introduction}

Prostate cancer (PC) is one of the most commonly diagnosed malignancies in men. Early diagnosis of cancer and timely detection of disease progression are crucial for the effective treatment and beneficial clinical outcome. Androgen-deprivation therapy (ADT) is commonly used in the treatment of PC (Keating et al. 2006). Despite some controversies surrounding the appropriate scope of use, there is evidence that ADT is effective at slowing tumor progression, reducing symptoms, and improving survival in PC patients. ADT is accompanied by a range of adverse effects such as acceleration of the age-related decline in bone mineral density, increasing adiposity and decreasing lean body mass within 3 to 12 months of initiation of treatment. The loss of muscle mass is associated with reduced muscular strength and increasing falls, fracture risk and ADT-induced fatigue. Exercise training has been proposed as natural and non-invasive strategy for ameliorating these adverse effects (Taafle 
et al. 2017, Ostergren et al. 2016, Basaria et al. 2006).

Randomized trials have demonstrated that the addition of a resistance training program to ADT therapy had many beneficial effects for PC patients and resulted in the mitigation of selected adverse effects. Studies comparing the impact of routine treatment on oncological patients with a specialized exercise program have shown a significant protective effect on the volume of muscle mass with the inclusion of a specialized exercise program (Battaglini et al. 2007, Coleman et al. 2003).

During the last decade, a major advancement in molecular biology was the discovery of non-coding RNAs, including microRNA (miRNA) which serve important biological functions. Since their discovery, miRNAs have shown many promising perspectives in a wide range of clinical applications, not only for diagnostic purposes, but in therapy as well. Results from numerous clinical studies have revealed a panel of miRNAs, which are deregulated in PC and may serve as promising biomarkers of PC risk, progression and potential therapeutic targeting. Similarly, miRNA expression levels also vary considerably depending on the mode of exercise and muscular pathology (Eisenberg et al. 2007, Polakovicova et al. 2016, Gerdes et al. 2014, Calin et al. 2012).

In serum and plasma, expression patterns of miRNAs in miRNA-1, miRNA -29b, miRNA-133a, miRNA-206, miRNA-208a, miRNA-208b miRNA-486 and miRNA-499 have shown differences in response to various endurance and strength training modalities (Zen et al. 2012, De Planell-Saguer et al. 2013, Chen et al. 2008, Baggish et al. 2011, Baggish et al. 2014, Mooren et al. 2013, Clauss et al. 2016, Aoi et al. 2013). These miRNAs could play a role also in myogenesis, muscle regeneration (Horak et al. 2016, Moresi et al. 2015, Kovanda et al. 2014), and in different models of muscle atrophy ( $\mathrm{Li}$ et al. 2017). On the other hand, different studies have shown a specific expression profile of miRNAs in several types of cancer including PC (Hasáková et al. 2017). Cumulative results show that these miRNAs could be involved in all steps of PC development, such as cell proliferation, differentiation, and progression (Filella et al. 2018).

To determine the relationship between the role of physical activity on PC patients and miRNAs, miRNA profiling needs to be performed. Thus, the aim of our present study was to investigate the impact of aspecialized strength-training program on physical and metabolic function and plasma levels of selected myogenic miRNAs (miRNA-1, miRNA-29b, miRNA-133a) in PC patients undergoing ADT.

\section{Methods}

\section{Patients and trial design}

The randomized open prospective study was conducted from August 2014 to October 2014. The protocol was approved by the Ethics committee for research projects established at the Faculty of Physical Education and Sport, Comenius University in Bratislava (Decision No. 10-1-13/FTVSUK).

Potential participants were primarily identified by their treating urologist/oncologist and referred to the study coordinator to confirm eligibility, describe the study, and obtain informed consent. In total, 32 prostate cancer patients were recruited and treated in two specialized health establishments in Bratislava, Slovak Republic. Every eligible patient had histologically confirmed localized prostate cancer, without metastatic disease or other active oncological illness except for skin conditions or anaemia. Patients were required to be treated with long-term ADT for 24-36 weeks. Inclusion criteria also included patients aged 60-78 years, a sedentary lifestyle without any exercise, structured resistance or aerobic training lasting more than 45 minutes per week in the previous 12 months. Exclusion criteria included evidence of heart disease, advanced hypertension, insulin dependent diabetes mellitus, chronic obstructive pulmonary disease, hepatic or liver ailments or presence of psychiatric illnesses. After the initiation phase of the trial, nine patients withdrew consent, leaving 23 patients for evaluation.

Participants were randomized to one of the two study arms: the control group (ADT + normal daily activities) or experimental group (ADT + supervised specialized strength training program). Study endpoints were assessed at baseline and after 16 weeks. The primary study endpoint was to investigate the effect of exercise training to changes in body composition, physical function, and muscle strength and cardiometabolic alterations in PC patients undergoing ADT. The prespecified secondary endpoint was to investigate the impact of the strength training program on plasma levels of selected myogenic miRNAs (miRNA-1, miRNA-29b and miRNA-133a) in these patients.

\section{Exercise training program}

Participants in the experimental group undertook 
progressive resistance training thrice a week for 16 weeks. Exercise training was carried out at the Faculty of Physical Education and Sport, Comenius University in Bratislava. Fifteen participants were placed in the experimental group and the training program was designed by recommendations for movement and activity of oncology patients, published by Schmitz et al. (2010). See the characterization of training program in Table 1.

Table 1. Characterization of training program.

\begin{tabular}{|c|c|c|c|c|c|c|}
\hline \multicolumn{7}{|c|}{ Experimental group } \\
\hline \multirow{2}{*}{$\begin{array}{l}\text { Duration } \\
\text { (month) }\end{array}$} & \multirow{2}{*}{$\begin{array}{l}\text { Training } \\
\text { (a week) }\end{array}$} & \multicolumn{4}{|c|}{ Characterization of training unit: } & \multirow[b]{2}{*}{$\begin{array}{l}\text { Rest periods } \\
\quad(\min )\end{array}$} \\
\hline & & Resistance & $\begin{array}{l}\text { No. of } \\
\text { series: }\end{array}$ & $\begin{array}{c}\text { No. of } \\
\text { exercise in } \\
\text { series }\end{array}$ & $\begin{array}{c}\text { Repetition of } \\
\text { exercises }\end{array}$ & \\
\hline \multicolumn{7}{|c|}{$1^{\text {st }}$ period: developing power capabilities } \\
\hline \multirow{3}{*}{1 month } & \multirow{3}{*}{3 times } & \multicolumn{4}{|c|}{2 units per week: practice exercise technique } & \\
\hline & & $30 \%$ & 2 & 5 & $10-15$ & $\begin{array}{c}2 \text { after exercise } \\
5 \text { after series }\end{array}$ \\
\hline & & \multicolumn{5}{|c|}{1 unit per week: compensating increase load, developing mobility } \\
\hline \multicolumn{7}{|c|}{$2^{\text {nd }}$ and $3^{\text {th }}$ periods: progressively increasing resistance } \\
\hline \multirow{3}{*}{2 months } & \multirow{3}{*}{3 times } & \multicolumn{5}{|c|}{2 units per week: suppressing muscle mass loss and strength development } \\
\hline & & $90-100 \%$ & 2 & 5 & $10-12$ & $\begin{array}{c}2 \text { after exercise } \\
5 \text { after series }\end{array}$ \\
\hline & & \multicolumn{5}{|c|}{1 unit per week: compensate the weight } \\
\hline \multicolumn{7}{|c|}{$4^{\text {th }}$ period: progressively increasing resistance } \\
\hline \multirow[b]{2}{*}{1 month } & \multirow[b]{2}{*}{3 times } & \multicolumn{5}{|c|}{2 units per week: suppressing muscle mass loss and strength development } \\
\hline & & $90-100 \%$ & 3 & 5 & $10-15$ & $\begin{array}{c}2 \text { after exercise } \\
5 \text { after series }\end{array}$ \\
\hline
\end{tabular}

Control group was without training

Assessments

At baseline and after 16 weeks of trial, patients were assessed by means of physical examination (body composition, functional ability, bone mineral density, and venous blood samples). Strength abilities were assessed on the third day.

Total RNA was extracted from $100 \mu 1$ of plasma using TRI Reagent ${ }^{\mathrm{TM}}$ Solution (Invitrogen ${ }^{\mathrm{TM}}$ ) according to the manufacturer's instructions and with use of phenolchloroform extraction. For quantitative real-time reversetranscription PCR analysis, a TaqMan MicroRNA Reverse Transcription Kit (Applied Biosystems) was used. Quantitative PCR was performed with the TaqMan Universal PCR Master Mix II (Applied Biosystems). Each sample was analyzed in triplicate. Every batch of amplifications included 3 water blanks as negative controls for each of the reverse-transcription and PCR steps. All data were collected and analyzed with LinReg PCR used the methods $\Delta \Delta \mathrm{Ct}$, as result we show expression fold change. We conducted TaqMan MicroRNA assays for hsa-miR-1, hsa-miR-29b-3p, hsa-miR-133a-3p (Invitrogen). The small RNAs (SNU6) frequently used for normalization of miRNA expression, was included as well. 


\section{Endpoints}

Study endpoints were assessed at baseline and 16 weeks. The primary study endpoint was to investigate the effect of exercise training to changes in body composition, physical function, and muscle strength and cardio-metabolic alterations in PC patients undergoing ADT. The prespecified secondary endpoint was to investigate the impact of the strength training program on plasma levels of selected myogenic miRNAs (miRNA-1, miRNA-29b, miRNA-133a) in these patients.

\section{Statistical analysis}

Data were analyzed using Minitab 17 (Minitab, Pennsylvania State University, USA). Statistical analyses were performed with independent and paired sample T-Tests.

\section{Results}

\section{Characteristics of the patients}

The randomization included 32 patients, 9 of whom withdrew consent, leaving 23 patients for evaluation, from August 2014 to October 2014. The average age of the patients was $70.69 \pm 7.5$ years in the experimental group, and $69.21 \pm 5.8$ years in the control group. The average weight was $90.5 \pm 14.5 \mathrm{~kg}$, height $173.3 \pm 21.7 \mathrm{~cm}$ in the experimental group, and $94.0 \pm$ $12.2 \mathrm{~kg}$ with $174.3 \pm 16.7 \mathrm{~cm}$ in the control group. The median BMI was $30.14 \pm 6.4 \mathrm{~kg} / \mathrm{m}^{2}$ in the experimental and $30.85 \pm 5.2 \mathrm{~kg} / \mathrm{m}^{2}$ in the control group (Table 2).

\section{Endpoints}

The primary study endpoint was to investigate the effect of exercise training to changes in body composition, physical function, and muscle strength and cardio-metabolic alterations in PC patients undergoing ADT. The primary endpoint difference of results at 16 th week are shown in Fig. 1A, 1B. There were no significant between-group differences in the changes of weight, BMI and bone mineral density.

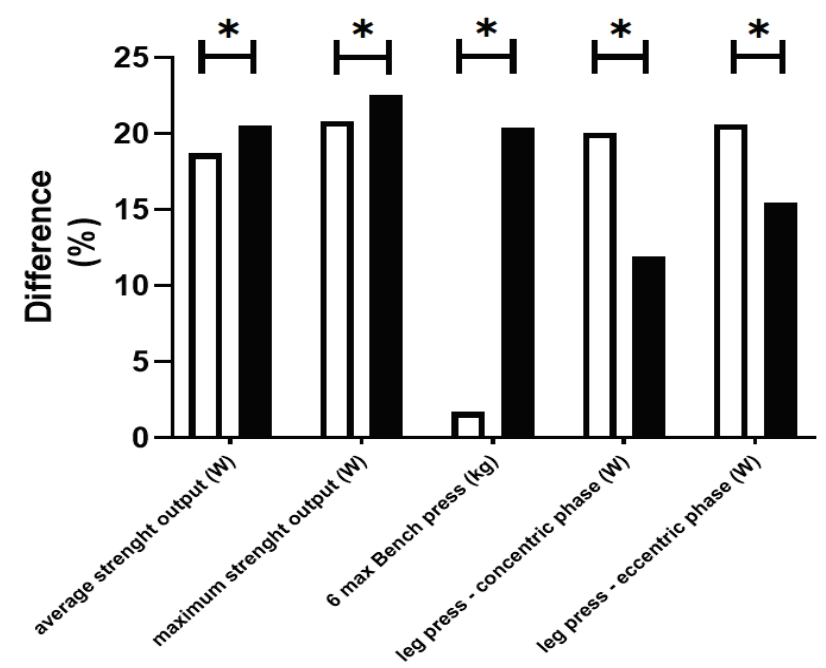

Fig. 1A Mean Percent Change from Baseline in Average and Maximal Strength Output, 6 max Bench Press, Concentric and Eccentric Phase of Leg Press. Within each group * indicate significant difference between baseline and the end of intervention (*p < 0.05). $\square$ - control group (ADT only), - experimental group (ADT + Training Program).

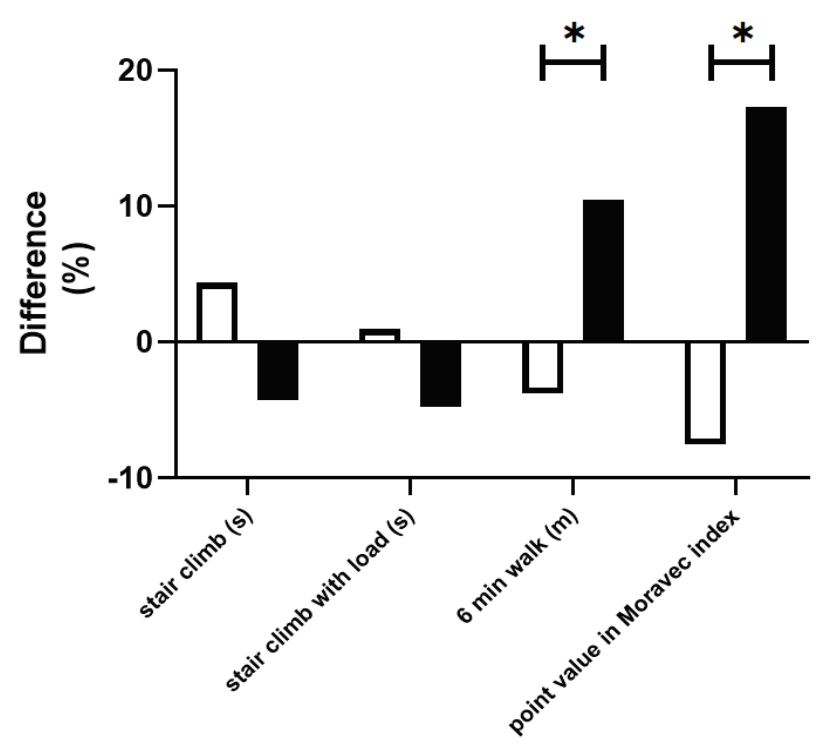

Fig. 1B Mean Percent Change from Baseline in Stair Climb, Stair Climb with Load, 6 min Walk, Point Value in Moravec index. Within each group * indicate significant difference between baseline and the end of intervention (*p < 0.05). $\square$ - control group (ADT only), - experimental group (ADT + Training Program).

Table 2. Baseline Characteristics of the Study Participants. Data expressed as mean \pm standard deviation.

\section{Characteristic}

ADT only

\section{Experimental Group $(n=15)$}

ADT and exercise intervention

$\begin{array}{lcc}\text { Age (years) } & 70.69 \pm 7.5 & 69.21 \pm 5.8 \\ \text { Weight }(\mathrm{kg}) & 90.5 \pm 14.5 & 94.0 \pm 12.2 \\ \text { Height }(\mathrm{cm}) & 173.3 \pm 21.7 & 174.3 \pm 16.7 \\ \text { BMI }\left(\mathrm{kg} / \mathrm{m}^{2}\right) & 30.14 \pm 6.4 & 30.85 \pm 5.2\end{array}$


Table 3. Changes in body composition, physical function and metabolic function.

\begin{tabular}{|c|c|c|c|c|c|c|}
\hline \multirow{2}{*}{ Parameter } & \multicolumn{3}{|c|}{$\begin{array}{l}\text { Control Group } \\
\text { ADT only }\end{array}$} & \multicolumn{3}{|c|}{$\begin{array}{c}\text { Experimental Group } \\
\text { ADT and Training Program }\end{array}$} \\
\hline & PRE & POST & $\begin{array}{l}\text { Difference } \\
\quad(\%)\end{array}$ & PRE & POST & $\begin{array}{l}\text { Difference } \\
\quad(\%)\end{array}$ \\
\hline \multicolumn{7}{|c|}{ Physical function } \\
\hline $\begin{array}{l}\text { Average strength } \\
\text { output }(W)\end{array}$ & $195.62 \pm 44.54$ & $232.24 \pm 40.92$ & +18.72 & $199.41 \pm 45.66$ & $240.31 \pm 22.24$ & $+20.51 *$ \\
\hline $\begin{array}{l}\text { Maximum strength } \\
\text { output }(W)\end{array}$ & $546.55 \pm 109.54$ & $660.35 \pm 111.1$ & +20.82 & $576.62 \pm 158.3$ & $706.67 \pm 129.7$ & $+22.55 *$ \\
\hline 6 max Bench press $(\mathrm{kg})$ & $32.78 \pm 7.11$ & $33.33 \pm 9.12$ & +1.69 & $39.62 \pm 14.73$ & $47.69 \pm 13.92$ & $+20.39 *$ \\
\hline $\begin{array}{l}\text { Leg press } \\
\text { - concentric phase }(W)\end{array}$ & $111.25 \pm 28.90$ & $133.58 \pm 27.44$ & +20.07 & $135.30 \pm 34.34$ & $151.46 \pm 38.74$ & $+11.95 *$ \\
\hline $\begin{array}{l}\text { Leg press } \\
\text { - eccentric phase }(W)\end{array}$ & $151.07 \pm 59.08$ & $182.22 \pm 55.02$ & +20.62 & $168.54 \pm 60.29$ & $194.60 \pm 65.49$ & $+15.44 *$ \\
\hline Stair climb $(s)$ & $10.77 \pm 1.55$ & $11.24 \pm 1.46$ & +4.36 & $11.07 \pm 2.34$ & $10.62 \pm 2.59$ & -4.25 \\
\hline Stair climb with load (s) & $11.45 \pm 1.48$ & $11.56 \pm 0.86$ & +0.96 & $11.45 \pm 2.40$ & $10.93 \pm 2.42$ & -4.76 \\
\hline 6 min walk $(m)$ & $564.13 \pm 56.23$ & $542.88 \pm 60.81$ & -3.77 & $575.64 \pm 71.31$ & $635.86 \pm 58.32$ & $+10.46 *$ \\
\hline $\begin{array}{l}\text { Point value in Moravec } \\
\text { index }\end{array}$ & $101.50 \pm 21.55$ & $94.38 \pm 23.18$ & -7.55 & $103.07 \pm 21.68$ & $120.93 \pm 18.51$ & $+17.33 *$ \\
\hline
\end{tabular}

\begin{tabular}{|c|c|c|c|c|c|c|}
\hline \multicolumn{7}{|c|}{ Metabolic function } \\
\hline $\begin{array}{l}\text { Total testosterone } \\
(\text { nmol/l) }\end{array}$ & $0.45 \pm 0.12$ & $0.449 \pm 0.13$ & -0.22 & $0.35 \pm 0.18$ & $0.69 \pm 0.21$ & $+95.74 *$ \\
\hline $\begin{array}{l}\text { Free testosterone } \\
\text { (nmol/l) }\end{array}$ & $5.18 \pm 2.33$ & $5.80 \pm 1.89$ & +12.07 & $3.62 \pm 1.12$ & $5.37 \pm 1.48$ & +48.34 \\
\hline Insulin (mlU/I) & $26.28 \pm 7.08$ & $47.32 \pm 7.72$ & +80.06 & $26.34 \pm 8.35$ & $21.42 \pm 7,93$ & $-22.94 *$ \\
\hline Interleukin-6 (pg/ml) & $2.80 \pm 1.05$ & $4.0 \pm 1.62$ & $+42.87^{*}$ & $3.26 \pm 1.22$ & $4.51 \pm 1.34$ & +38.36 \\
\hline$P S A(\mu g / l)$ & $0.22 \pm 0.08$ & $0.78 \pm 0.21$ & +255.62 & $0.51 \pm 0.28$ & $0.61 \pm 0.21$ & +18.91 \\
\hline Cortisol (nmol/l) & $538.68 \pm 121.88$ & $441.23 \pm 118.7$ & -22.08 & $435.68 \pm 84.46$ & $399.57 \pm 94.9$ & -9.03 \\
\hline
\end{tabular}

${ }^{*} \mathrm{p}=<0.05$ with the use of paired t-test for the comparison between the trial entry and the end of study. Data expressed as mean \pm standard deviation.

Impact of $\mathrm{ADT}$ and exercise intervention showed significant increase (experimental group vs control group) in lean body mass $(+4.65 \%, \mathrm{p}=0.02$ vs $1.16 \%, \mathrm{p}=0.798)$, average strength output $(+20.51 \%$, $\mathrm{p}=0.006$ vs $+18.72 \%, \mathrm{p}=0.318)$ and maximum strength output $(+22.51 \%, p=0.04$ vs $+20.82 \%, p=0.318)$ (Fig. 1A). There were significantly improved physical functions (experimental group vs control group) in the 6 max bench press $(+20.39 \%, p=0.041$ vs +1.69 , $\mathrm{p}=0,176)$, concentric $(+11.95 \%, \mathrm{p}=0.005 \mathrm{vs}+20.07 \%$, $\mathrm{p}=0,051)$ and eccentric $(+15.44 \%, \mathrm{p}=0.049 \mathrm{vs}+20.62 \%$, $\mathrm{p}=0.081$ ) phase of leg press (Fig. 1A), 6 min walk $(+10.46 \%, p=0.045$ vs $-3.77 \%, p=0,528)$ and in point value in Moravec index $(+17.33 \%, \mathrm{p}=0.006$ vs $-7.55 \%$, $\mathrm{p}=0.855$ ) (Fig. 1B). ADT with or without exercise intervention indicated no significant changes in stair climbing (Table 3 - Physical function).

The rates of metabolic disease progression including selected biochemical levels were lower in the experimental group (ADT + training program) than in the control group (ADT only). In the experimental group were significantly reduced insulin serum levels (PRE: $26.336 \mathrm{mIU} / 1$, POST: $21.422 \mathrm{mIU} / 1$, $-22.94 \%, p=0.039)$ and were significantly increased the levels of free testosterone (PRE: $0.352 \mathrm{nmol} / \mathrm{l}$, POST: $0.689 \mathrm{nmol} / 1,+95.74 \%, \mathrm{p}=0.021)$ compared to control group. Interleukin-6 was significantly increased in the control group (PRE: $2.799 \mathrm{pg} / \mathrm{ml}$, POST: $3.999 \mathrm{pg} / \mathrm{ml}$, $+42.87 \%, \mathrm{p}=0.035)$ compared to the experimental group (PRE:3.256 pg/ml, POST: $4.505 \mathrm{pg} / \mathrm{ml}, 38.36 \%$, $\mathrm{p}=0.145)($ Table 3 - Metabolic Changes $)$. 

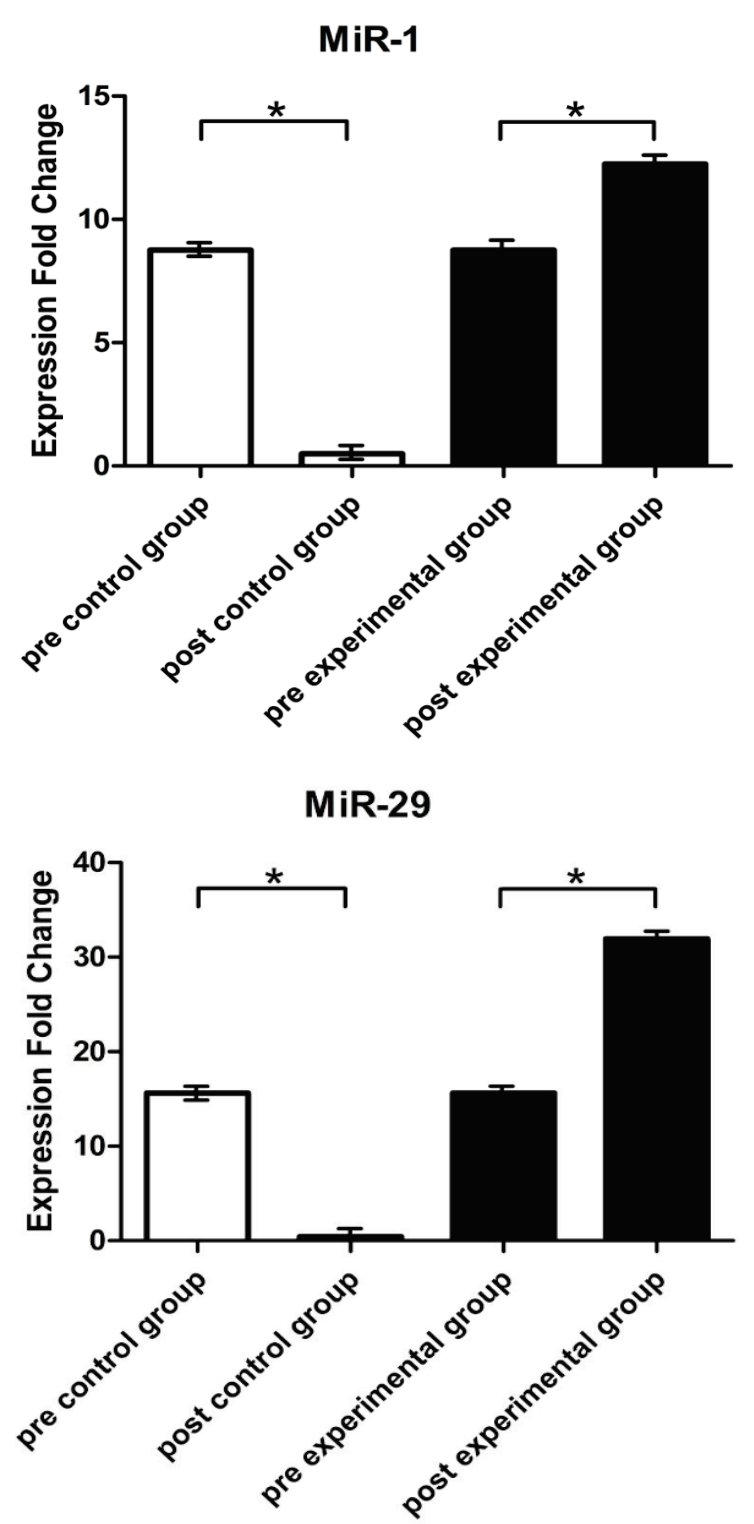

MiR-133

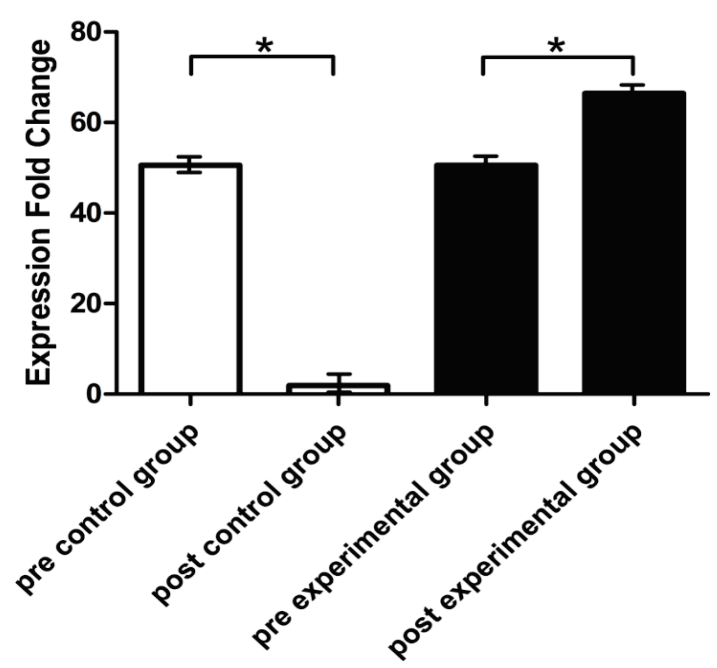

Fig. 2. Fold change of expression levels of miR-1, miR-29b, miR-133a at baseline and after 16 weeks. $\left({ }^{*} p<0.05-\right.$ within each group $*$ indicate significant difference between baseline and the end of intervention and the control).

\section{MicroRNA analyses}

In an effort to identify miRNAs involved in post-ADT cardiovascular changes, we compared miRNA expression profiles in the control and experimental group at baseline and after 16 weeks of intervention. The expression fold-change of miRNA-1, miRNA-29 and miR-133 significantly decreased in control group after 16 weeks of ADT. Real-time PCR analysis indicated that the expression fold-change of miRNA-1, miRNA-29 and miR-133 in experimental group were significantly increased in response to 16 weeks of ADT and strength training program (Fig. 2).

\section{Discussion}

In this randomized trial, we have demonstrated that the addition of a strength training (ST) program to ADT had many positive effects for patients and resulted in the mitigation of selected adverse effects. Previously it has been shown, that a regular exercise program was effective in preventing muscle mass loss (Segal et al. 2009). Studies comparing the impact of routine treatment on oncological patients with a specialized exercise program have resulted in a significant protective effect on the volume of muscle mass with the inclusion of a specialized exercise program (Battaglini et al. 2007, Coleman et al. 2003, Collins et al. 2012).

We hypothesized that in patients on ADT, strength training would increase muscle power, thereby improving body composition and physical function in older men with PC. We demonstrated a significant increase in average $(+20.51 \%, \mathrm{p}=0.006)$ and maximum $(+22.55 \%, \mathrm{p}=0.040)$ strength output in the experimental group compared to the control group. Hanson and colleagues reported the results of a 12 week ST regimen on 17 men with PC on ADT. They found that ST significantly increased average strength output $(+17 \%)$ in ADT-treated prostate cancer patients (Hanson et al. 2013). LeStayo et al. (2011) found an increase in average strength output $(+28.91 \%)$ in an oncological group without ADT.

Lean body mass is a frequent primary endpoint in randomized trials that follow the efficacy of an exercise program on the body composition of oncology patients using ADT (Galvao et al. 2006). We assume that there are two opposing changes occurring, namely a decrease in visceral reserves and an increase in the volume of muscle mass. The results of our study found a statistically significant increase in lean body mass by 
$4.65 \%$. Studies by Cormie and colleagues showed an almost identical, statistically significant alteration in the proportion of lean body mass, at a level of 3-4\%, after a three-month power program (Cormie et al. 2014). We did not either see a significant change in the experimental or control group when we evaluated changes in body mass index or body weight. Body mass and weight are highly dependent on the systemic regulation of storage and consumption of energy supplies and on the management of metabolism. Different ranges and prevalence of metabolic disorders in subject groups could be the main reasons for the lack of statistically significant changes in the body mass index or body weight.

Small endogenous non-coding RNAs (18-25 nt) known as miRNAs can prevent protein expression through cleavage of specific target mRNAs or through inhibition of their translation (Bartel 2004). miRNAs represent an interesting target for biomarker discovery. Every miRNA can interact with various cellular pathways, and therefore alterations in the expression of few miRNAs may impact the deregulation of several cellular processes contributing to cancer complexity. The issue of early cancer detection represents a promising field for miRNA-based diagnostics, as currently there is a lack of early detection methods and screening tests in many types of cancer. Recent clinical and experimental studies have demonstrated that microRNAs have distinct expression profiles in normal and cancer cells, which are tissue specific (Franco et al. 2011), microRNAs can also influence all hallmarks of cancer either by promoting or suppressing tumour development and progression (Vanacore et al. 2017).

Kojima et al. (2012) observed significantly lower expression levels of miRNA-1 and miRNA-133a in PC tissues compared with non-prostatic cancer tissue PC and suggested that these changes are key steps in oncogenesis or progression in PC. They also demonstrated that restoration of miRNA-1 or miRNA-133a expression suppressed cancer cell proliferation, migration, and invasion in PC. In addition, several studies have shown that miRNA-133a is under-expressed in pancreatic ductal adenocarcinoma, colon cancer, and tongue squamous cell carcinoma (Basaria et al. 2006). In tongue squamous cell carcinoma miRNA-133a inhibited cell proliferation and induced apoptosis (Wong et al. 2008). In our study, we detected significantly lower expression levels of miRNA-1 in the control group while a significantly higher expression level was noted in the experimental group. A similar trend was noted in the level of expression of miRNA-133a, levels were significantly increased in the experimental group compared to control. Kojima et al. (2012) have shown that the restoration of miRNA-1 or miRNA-133a expression suppressed cancer cell proliferation, migration, and invasion in PC. Several reports demonstrated that miRNA-133a was underexpressed in pancreatic ductal adenocarcinoma, colon cancer and tongue squamous cell carcinoma (Basaria et al. 2006), and in tongue squamous cell carcinoma, miRNA-133a inhibited cell proliferation and induced apoptosis (Wong et al. 2008). Taken together, miRNA-1 and miRNA-133a appear to be important miRNAs, acting as tumor suppressors in several human cancers including PC.

Thus, miRNAs have been reported to play fundamental roles in diverse biological and pathological processes, including muscle development and regeneration. Different miRNAs, including miRNA-1, miRNA-133 and miRNA-206 have been shown to participate in myogenesis and muscle regeneration (Horak et al. 2016, Moresi et al. 2015, Kovanda et al. 2014). In contrast, miRNAs have also been shown to play a role in different models of muscle atrophy, including miRNA-1, miRNA-133, miRNA-23a, miRNA-21, miRNA-27, miRNA-628, miRNA-431 and miRNA-206 (Li et al. 2017). Li et al. identified miRNA-29b induction and activity as a novel pathway contributing to muscle atrophy. The expression of miRNA-29b is significantly increased in in vivo and in vitro models of muscle atrophy. In our study, levels of miRNA-29b in the control group were lower than in the experimental group.

\section{Conclusions}

In conclusion, strength training in combination with $\mathrm{ADT}$ in the treatment of $\mathrm{PC}$, alters the levels of specific microRNAs, suggesting the possibility that these may serve as relevant biomarkers of cell proliferation and prostate cancer.

\section{Conflict of Interest}

There is no conflict of interest.

\section{Acknowledgements}

This publication is the result of the project implementation: VEGA 1/0949/15, APVV-14-0416 and MZ SR 2016/13-FAUK-1. 


\section{References}

AOI W, ICHIKAWA H, MUNE K, TANIMURA Y, MIZUSHIMA K, NAITO Y, YOSHIKAWA T: Muscle-enriched microRNA miR-486 decreases in circulation in response to exercise in young men. Front Physiol 4: 80, 2013.

BAGGISH AL, HALE A, WEINER RB, LEWIS GD, SYSTROM D, WANG F, WANG TJ, CHAN SY: Dynamic regulation of circulating microRNA during acute exhaustive exercise and sustained aerobic exercise training. J Physiol 589: 3983-3994, 2011.

BAGGISH AL, PARK J, MIN PK, ISAACS S, PARKER BA, THOMPSON PD, TROYANOS C, D'HEMECOURT P, DYER S, THIEL M, HALE A, CHAN SY: Rapid upregulation and clearance of distinct circulating microRNAs after prolonged aerobic exercise. J Appl Physiol 116: 522-531, 2014.

BARTEL DP: MicroRNAs: genomics, biogenesis, mechanism, and function. Cell 116: 281-297, 2004.

BASARIA S, MULLER DC, CARDUCCI MA, EGAN J, DOBS AS: Hyperglycemia and insulin resistance in men with prostate carcinoma who receive androgen-deprivation therapy. Cancer 106: 581-588, 2006.

BATTAGLINI C, BOTTARO M, DENNEHY C, RAE L, SHIELDS E, KIRK D, HACKNEY AC: The effects of an individualized exercise intervention on body composition in breast cancer patients undergoing treatment. Sao Paulo Med J 125: 22-28, 2007.

CALIN GA, CROCE CM: MicroRNA signatures in human cancers. Nat Rev Cancer 6: 857-866, 2006.

CHEN X, BA Y, MA L, CAI X, YIN Y, WANG K, GUO J, ZHANG Y, CHEN J, GUO X, LI Q, LI X, WANG W, ZHANG Y, WANG J, JIANG X, XIANG Y, XU C, ZHENG P, ZHANG J, LI R, ZHANG H, SHANG X, GONG T, NING G, WANG J, ZEN K, ZHANG J, ZHANG CY: Characterization of microRNAs in serum: A novel class of biomarkers for diagnosis of cancer and other diseases. Cell Res 18: 997-1006, 2008.

CLAUSS S, WAKILI R, HILDEBRAND B, KÄÄB S, HOSTER E, KLIER I, MARTENS E, HANLEY A, HANSSEN H, HALLE M, NICKEL T: microRNAs as biomarkers for acute atrial remodeling in marathon runners (The miRathon study - A sub-study of the Munich marathon study) PLoS ONE 11: 1553, 2016.

COLEMAN EA, COON S, HALL-BARROW J, RICHARDS K, GAYLOR D, STEWART B: Feasibility of exercise during treatment for multiple myeloma. Cancer Nurs 26: 410-419, 2003.

COLLINS L, BASARIA S: Adverse effects of androgen deprivation therapy in men with prostate cancer: A focus on metabolic and cardiovascular complications. Asian J Androl 14: 222-225, 2012.

CORMIE P, GALVÃO DA, SPRY N, JOSEPH D, TAAFFE DR, NEWTON RU: Functional benefits are sustained after a program of supervised resistance exercise in cancer patients with bone metastases: Longitudinal results of a pilot study. Support Care Cancer 22: 1537-1548, 2014.

DE PLANELL-SAGUER M, RODICIO MC: Detection methods for microRNAs in clinic practice. Clin Biochem 46: 869-878, 2013.

EISENBERG I, ERAN A, NISHINO I, MOGGIO M, LAMPERTI C, AMATO AA, LIDOV HG, KANG PB, NORTH KN, MITRANI-ROSENBAUM S, FLANIGAN KM, NEELY LA, WHITNEY D, BEGGS AH, KOHANE IS, KUNKELA KM: Distinctive patterns of microRNA expression in primary muscular disorders. Proc Natl Acad Sci USA 105: 17016-17021, 2007.

FRANCO R, CARAGLIA M, FACCHINI G, ABBRUZZESE A, BOTTI G: The role of tissue microarray in the era of target-based agents. Expert Rev Anticancer Ther 11: 859-869, 2011.

FILELLA X, FERNÁNDEZ-GALAN E, FERNÁNDEZ BONIFACIO R, FOJ L: Emerging biomarkers in the diagnosis of prostate cancer. Pharmacogenomics Pers Med 11: 83-94, 2018.

GALVÃO DA, NOSAKA K, TAAFFE DR, SPRY N, KRISTJANSON LJ, MCGUIGAN MR, SUZUKI K, YAMAYA K, NEWTON RU: Resistance training and reduction of treatment side effects in prostate cancer patients. Med Sci Sports Exerc 38: 2045-2052, 2006.

GERDES MJ, SOOD A, SEVINSKY C, PRIS AD, ZAVODSZKY MI, GINTY F: Emerging understanding of multiscale tumor heterogeneity. Front Oncol 4: 366, 2014.

HANSON ED, SHEAFF AK, SOOD S, MA L, FRANCIS JD, GOLDBERG AP, HURLEY BF: strength training induces muscle hypertrophy and functional gains in black prostate cancer patients despite androgen deprivation therapy. J Gerontol Biol Sci Med Sci 68: 490-498, 2013. 
HASÁKOVÁ K, BEZAKOVA J, VICIAN M, REIS R, ZEMAN M, HERICHOVA I: Gender-Dependent Expression of Leading and Passenger Strand of miR-21 and miR-16 in Human Colorectal Cancer and Adjacent Colonic Tissues. Physiol Res 66 (Suppl. 4): S575-S582, 2017.

HORAK M, NOVAK J, BIENERTOVA-VASKU J: Muscle-specific microRNAs in skeletal muscle development. Dev Biol 410: 1-13, 2016.

KEATING NL, O'MALLEY AJ, SMITH MR: Diabetes and cardiovascular disease during androgen deprivation therapy for prostate cancer. $J$ Clin Oncol 24: 4448-4456, 2006.

KOJIMA S, CHIYOMARU T, KAWAKAMI K, YOSHINO H, ENOKIDA H, NOHATA N, FUSE M, ICHIKAWA T, NAYA Y, NAKAGAWA M, SEKI N: Tumour suppressors miR-1 and miR-133a target the oncogenic function of purine nucleoside phosphorylase (PNP) in prostate cancer. Br J Cancer 106: 405-413, 2012.

KOVANDA A, REZEN T, ROGELJ B: MicroRNA in skeletal muscle development, growth, atrophy, and disease. Wiley Interdiscip Rev RNA 5: 509-525, 2014.

LASTAYO PC, MARCUS RL, DIBBLE LE, SMITH SB, BECK SL: Eccentric exercise versus usual-care with older cancer survivors: the impact on muscle and mobility--an exploratory pilot study. BMC Geriatr 11: 5, 2011.

LI J, CHAN MC, YU Y, BEI Y, CHEN P, ZHOU Q, CHENG L, CHEN L, ZIEGLER O, ROWE GC, DAS S, XIAO J: miR-29b contributes to multiple types of muscle atrophy. Nat Commun 8: 15201, 2017.

MORESI V, MARRONCELLI N, COLETTI D, ADAMO S: Regulation of skeletal muscle development and homeostasis by gene imprinting, histone acetylation and microRNA. Biochim Biophys Acta 1849: 309-316, 2015.

MOOREN FC, VIERECK J, KRÜGER K, THUM T: Circulating microRNAs as potential biomarkers of aerobic exercise capacity. Am J Physiol Heart Circ Physiol 306: 557-563, 2014.

ØSTERGREN PB, KISTORP C, BENNEDBÆK FN, FABER J, SØNKSEN J, FODE M: The use of exercise interventions to overcome adverse effects of androgen deprivation therapy. Nat Rev Urol 13: 353-364, 2016.

POLAKOVIČOVÁ M, MUSIL P, LACZO E, HAMAR D, KYSELOVIČ J: Circulating microRNAs as potential biomarkers of exercise response. Int J Mol Sci 17: 1553, 2016.

SCHMITZ KH, COURNEYA KS, MATTHEWS C, DEMARK-WAHNEFRIED W, GALVÃO DA, PINTO BM, IRWIN ML, WOLIN KY, SEGAL RJ, LUCIA A, SCHNEIDER CM, VON GRUENIGEN VE, SCHWARTZ AL: American College of Sports Medicine Roundtable on Exercise Guidelines for Cancer Survivors. Med Sci Sports Exerc 42: 1409-1426, 2010.

SEGAL RJ, REID RD, COURNEYA KS, SIGAL RJ, KENNY GP, PRUD'HOMME DG, MALONE SC, WELLS GA, SCOTT CG, SLOVINEC D'ANGELO ME: Randomized controlled trial of resistance or aerobic exercise in men receiving radiation therapy for prostate cancer. J Clin Oncol 27: 344-351, 2009.

TAAFFE DR, NEWTON RU, SPRY N, JOSEPH D, CHAMBERS SK GARDINER RA, WALL BA, CORMIE P, BOLAM KA, GALVÃO DA: Effects of different exercise modalities on fatigue in prostate cancer patients undergoing androgen deprivation therapy: A year-long randomised controlled trial. Eur Urol 72: 293-299, 2017.

VANACORE D, BOCCELLINO M, ROSSETTI S, CAVALIERE C, D'ANIELLO C, DI FRANCO R, ROMANO FJ, MONTANARI M, LA MANTIA E, PISCITELLI R, NOCERINO F, CAPPUCCIO F, GRIMALDI G, IZZO A, CASTALDO L, PEPE MF, MALZONE MG, IOVANE G, AMETRANO G, STIUSO P, QUAGLIUOLO L, BARBERIO D, PERDONÀ S, MUTO P, MONTELLA M, MAIOLINO P, VENEZIANI BM, BOTTI G, CARAGLIA M, FACCHINI G: MicroRNAs in prostate cancer: an overview. Oncotarget 8: 50240-50251, 2017.

WAMPLER MA, TOPP KS, MIASKOWSKI C, BYL NN, RUGO HS, HAMEL K: Quantitative and clinical description of postural instability in women with breast cancer treated with taxane chemotherapy. Arch Phys Med Rehabil 88: 1002-1008, 2007.

ZEN K, ZHANG CY: Circulating microRNAs: A novel class of biomarkers to diagnose and monitor human cancers. Med Res Rev 32: 326-348, 2012. 